\title{
In silico Structural, Functional and Phylogenetic Analyses of cellulase from Ruminococcus albus
}

\author{
Anila Hoda ${ }^{*} \mathbb{D}$, Myqerem Tafaj and Enkelejda Sallaku
}

\begin{abstract}
Background: Cellulose is the primary component of the plant cell wall and an important source of energy for the ruminant and microbial protein synthesis in the rumen. Cell wall content is digested by anaerobic fermentation activity mainly of bacteria belonging to species Fibrobacter succinogenes, Ruminicoccus albus, Ruminococcus flavefaciens, and Butyrivibrio fibrisolvens. Bacteria belonging to the species Ruminococcus albus contain cellulosomes that enable it to adhere to and digest cellulose, and its genome encodes cellulases and hemicellulases.

This study aimed to perform an in silico comparative characterization and functional analysis of cellulase from Ruminococcus albus to explore physicochemical properties and to estimate primary, secondary, and tertiary structure using various bio-computational tools.

The protein sequences of cellulases belonging to 6 different Ruminococcus albus strains were retrieved using UniProt. In in silico composition of amino acids, basic physicochemical characteristics were analyzed using ProtParam and Protscale. Multiple sequence alignment of retrieved sequences was performed using Clustal Omega and the phylogenetic tree was constructed using Mega X software. Bioinformatics tools are used to better understand and determine the 3D structure of cellulase. The predicted model was refined by ModRefiner. Structure alignment between the best-predicted model and the template is applied to evaluate the similarity between structures.

Results: In this study are demonstrated several physicochemical characteristics of the cellulase enzyme. The instability index values indicate that the proteins are highly stable. Proteins are dominated by random coils and alpha helixes. The aliphatic index was higher than 71 providing information that the proteins are highly thermostable. No transmembrane domain was found in the protein, and the enzyme is extracellular and moderately acidic. The best tertiary structure model of the enzyme was obtained by the use of Raptor $X$, which was refined by ModRefiner. Raptor X suggested the 6Q1I_A as one of the best homologous templates for the predicted 3D protein structure. Ramachandran plot analysis showed that $90.1 \%$ of amino acid residues are within the most favored regions.

Conclusions: This study provides for the first time insights about the physicochemical properties, structure, and function of cellulase, from Ruminococcus albus, that will help for detection and identification of such enzyme in vivo or in silico.
\end{abstract}

Keywords: In silico analysis, Physicochemical properties, Rampage, Phylogenetic relationships, Structure alignment

*Correspondence: ahoda@ubt.edu.al

Department of Animal Sciences, Faculty of Agriculture and Environment,

Agricultural University of Tirana, Koder Kamez, 1029 Tirana, Albania

(c) The Author(s). 2021 Open Access This article is licensed under a Creative Commons Attribution 4.0 International License, which permits use, sharing, adaptation, distribution and reproduction in any medium or format, as long as you give appropriate credit to the original author(s) and the source, provide a link to the Creative Commons licence, and indicate if changes were made. The images or other third party material in this article are included in the article's Creative Commons licence, unless indicated otherwise in a credit line to the material. If material is not included in the article's Creative Commons licence and your intended use is not permitted by statutory regulation or exceeds the permitted use, you will need to obtain permission directly from the copyright holder. To view a copy of this licence, visit http://creativecommons.org/licenses/by/4.0/. 


\section{Background}

Cellulases are hydrolytic enzymes that hydrolyze $\beta-1,4-$ glycosidic linkage within cellulose. The complete hydrolysis of cellulose is obtained by the action of three types of cellulases namely endoglucanase, exoglucanase, and $B$-glucosidase. Cellulose is the primary component of the plant cell wall and an important source of energy for the ruminant and microbial protein synthesis in the rumen. The importance of fiber digestion is increasing, especially in the development of feeding strategies for ruminants. The cell wall contents are digested in both the liquid and solid phases of the rumen contents by anaerobic fermentation mainly through rumen bacteria. According to Henderson et al. [1], Prevotella, Butyrivibrio, Ruminococcus, and other unclassified members of Lachnospiraceae, Ruminococcaceae, Bacteroidales, and Clostridiales accounted for $67.1 \%$ in a pool of bacterial sequence data collected from different ruminant species fed different diets. These might be considered a "core bacterial microbiome".

The cultivable bacteria mostly involved in fiber digestion are Fibrobacter succinogenes, Ruminicoccus albus, Ruminococcus flavefaciens, and Butyrifibrio fibrisolvens [2]. Bacteria belonging to the species Ruminococcus albus contain cellulosomes that enable them to adhere to and digest cellulose, and its genome encodes cellulases and hemicellulases [3]. Ruminococcus albus is a primary cellulose degrader that produces acetate usable by its bovine host. The complete genome of this bacteria is fully described by Suen et al. [3]. Densities of the rumen fiber-digested bacterial species, including Ruminococcus albus were influenced by different feed-related factors (concentrate level, fiber quality, and particle size, among others) [4-6], as well as animal-related factors [6].

Very little is known about the structure of cellulases. Islam and Roy (2018) [7] have isolated and characterized by morphological and biochemical analysis the cellulases from Paenibacillus sp., Bacillus sp., and Aeromonas sp. of 3D protein structures. Experimental determination of $3 \mathrm{D}$ protein structures is very difficult and complex [8], also expensive and timeconsuming; therefore, other approaches have to be considered [9]. In this context, bioinformatics tools are of great interest and are widely applied for the prediction of 3D protein structure in several cases $[8$, 10-12], or gene analysis [13]. Cellulase from genus Bacillus is previously in silico analyzed [14]. The aim of the present study is the characterization by the use of bioinformatics tools of enzyme cellulase from Ruminococcus albus not previously investigated. The present study envisaged the computational prediction of the secondary and tertiary structures of cellulase (P23660), structure evaluation, and the functional characterization including protein-protein interaction.

\section{Methods}

Sequence retrieval, alignment and phylogenetic analysis Cellulase protein sequence from Ruminococcus albus was retrieved in FASTA format (accession no. P23660) from UniProt (Universal Protein Resource (https://www. uniprot.org/)) and served as a query for BLAST at http://blast.ncbi.nlm.nih.gov/Blast.cgi against a nonredundant protein database. Clustal Omega (version 1.2.4) algorithm was used for the alignment of retrieved protein sequences through multiple sequence alignment.

The same sequence was used as a query sequence for the PSI-BLAST against protein data bank (PDB) at http://blast.ncbi.nlm.nih.gov/Blast.cgi to identify its homologous structures. PRALINE at http://www.ibi.vu. $\mathrm{nl} /$ programs/pralinewww/ was used for the alignment of query and template sequences.

Phylogenetic tree of all the total 6 bacterial cellulase protein sequences from different Ruminococcus albus strains has been constructed through the maximum likelihood method based on JTT matrix-based model [15] by the use of MEGAX [16] software. The reliability of internal branches was assessed by using 1000 bootstrap replicates, and gaps were detected in the analysis.

\section{Primary sequence analysis and subcellular localization}

The online software, Protparam [17] at http://expasy. org/tools/protparam.html was used for the determination of physicochemical properties of selected sequences such as amino acid composition, aliphatic index (AI), isoelectric point (pI), instability index (II), number of positive and negative charged residues, grand average of hydropathicity (GRAVY), and extinction coefficient (EC).

CELLO subcellular localization predictor at http:// cello.life.nctu.edu.tw/ [18], TMHMM server v. 2.0 [19], and PSLpred, a SVM-based method for the subcellular localization of prokaryotic proteins at http://crdd.osdd. net/raghava/pslpred were employed to predict the subcellular position.

\section{Secondary structure, topology, and signal peptide prediction}

To predict the secondary structure of the protein, two online server SOPMA at https://npsa-prabi.ibcp.fr/cgibin/npsa_automat.pl?page $=$ npsa_sopma.html and PSIP RED v3.3 (http://bioinf.cs.ucl.ac.uk/psipred/) [20] were applied, and results obtained from these tools were also compared to determine $\alpha$-helix, $\beta$-sheet, turns, and loops.

TopCons [21] (http://topcons.cbr.su.se/) predicts consensus topology of membrane proteins and signal peptides (SPs). Signal P 4.1 server [22] at http://www.cbs.dtu. $\mathrm{dk} /$ services/SignalP/ searches for the presence of signal peptide cleavage sites. 
3D structure prediction using homology modeling, model evaluation, and refinement

The full 3D structure of cellulase from Ruminococcus albus is not available in the Protein Data Bank (PDB). Therefore, we used five online homology modeling programs to generate a 3D structural model for cellulase, using the FASTA format of the query sequence (P23660). The tertiary structure of query sequence was predicted through these programs: Expasy SWISSMODEL (ProMod Version 3.70), Phyre2 [23] (http:// www.sbg.bio.ic.ac.uk/phyre2/html/page.cgi?id=index), RaptorX structure prediction server, (http://raptorx. uchicago.edu/StructurePrediction/predict/), $\quad(\mathrm{PS})^{2}$-V2 [24] (http://ps2.life.nctu.edu.tw/), and LOMETS (Local Meta-Threading-Server) [25] which is a protein structure prediction server at http://zhang lab.ccmb.med.umichedu/LOMET S/).

The ModRefiner (http://zhanglab.ccmb.med.umich. edu/ModRefiner/), which is a high-resolution protein structure refiner, was used to improve the physical quality of structures. The built and refined models were evaluated via Rampage at http://mordred.bioc.cam. acukrapper/rampage.php. The Ramachandran plots were depicted for each model. The model with the least number of residues in the disallowed region was selected for further studies. The model in specified format was submitted to Protein Data Bank.

\section{Structure alignment}

The best predicted 3D structure of the protein was structurally aligned and compared with the selected template structure from PDB. The alignment was done by the use of Dali server (http://ekhidna.biocenter.helsinki. fi/dali/) [26], by superposition of the atomic coordinate sets and a minimal root mean square deviation (RMSD) between the structures. The RMSD of two aligned structures indicates their divergence from one another.

\section{Functionally analysis}

For functional analysis CYS_REC tool (http://linux1. softberry.com/berry.phtml) was used to identify the position of cysteine and compute the most probable SS bond pattern of pairs in protein [27]. The set of conserved amino acid residues were analyzed using Motif search tool (http://www.genome.jp/tools/motif/). COFACTOR at http://zhang lab.ccmb.med.umich.edu/ COFACTOR/ predicts the biological function of proteins based on their structure, sequence, and protein-protein interaction (PPI).

Identification of protein-protein interaction was carried out by STRING 11.0 (https://string-db.org/) [28] which is used to construct a protein-protein interaction network for different known and predicted protein interactions.

Pocket regions are defined by the use of several online servers, GHECOM (Grid-based HECOMi finder) server at http://strcomp.protein.osaka-u.ac.jp/ghecom/ and CastP server (http://sts.bioe.uic.edu/castp/). Depth (http://mspc.bii.a-star.edu.sg/tankp/help.html) was used for predicting depth, cavity sizes, ligand binding sites, and PKA.

\section{Results}

Sequence retrieval, alignment and phylogenetic analysis The amino acid sequence of the cellulase enzyme (P23660) was retrieved from UniProt database in FASTA format. This sequence served as the query for BLAST and six cellulase sequences were obtained, with the similarity of at least $84 \%$, belonging to different strains of Ruminococcus albus (Table 1). The total number of amino acid residues ranged from 364 to 414, with molecular weights that lie between 41,218 to $45,880 \mathrm{Da}$. They belong to endoglucanase and $ß$-glucanase. The cellulases show the different catalytic mechanisms of the endohydrolysis of (1 to > 4)-beta-D-glucosidic linkages in cellulose, lichenin and cereal beta-D-glucans and endohydrolysis of ( 1 to > 4)-beta-D-xylosidic linkages in xylans.

A BLASTp search against Protein Data Bank (PDB) was carried out, to find the most suitable protein structures as templates. The results of the BLASTp are displayed in Table 2, which shows the first 10 hits with the highest scores. The query coverage is higher than 93\%, and the percentage of identity ranged from 35.15 to $44.96 \%$.

Figure S1 shows the multiple sequence alignment for cellulases from different strains of Ruminococcus albus, obtained by Clustal Omega software. All sequences were highly conserved, with absolute conservation regions $\left(^{*}\right)$

Table 1 Characterization of retrieved sequences of cellulases for different $R$. albus strains using UniProt tool

\begin{tabular}{|c|c|c|c|c|c|c|c|}
\hline No. & Organism & Accession number & Protein & Number of aa & Molecular weight $(\mathrm{Da})$ & Molecular function & Family \\
\hline 1. & Ruminococcus albus & P23660 & Endoglucanase A & 364 & 41,218 & Glycosidase, Hydrolase & GH5 \\
\hline 2. & Ruminococcus albus & A0A011UFY5 & Endoglucanase & 413 & 45,742 & Glycosidase, & $\mathrm{GH} 5$ \\
\hline 3. & Ruminococcus albus & A0A1H7KSB4 & Endoglucanase & 413 & 45,676 & Glycosidase, & GH5 \\
\hline 4. & Ruminococcus albus & A0A $111 \mathrm{KHA} 3$ & Endoglucanase & 413 & 45,815 & Glycosidase, & $\mathrm{GH} 5$ \\
\hline 5. & Ruminococcus albus & Q59733 & Beta-1,4-D-glucanase & 414 & 45,880 & Glycosidase, Hydrolase & GH5 \\
\hline 6. & Ruminococcus albus & E6UGl8 & Cellulase & 410 & 45,776 & Glycosidase, Hydrolase & GH5 \\
\hline
\end{tabular}


Table 2 The first 10 hits with the highest scores of BLASTp on the cellulase sequence against Protein Data Bank (PDB)

\begin{tabular}{|c|c|c|c|c|c|c|c|c|c|}
\hline No. & $\begin{array}{l}\text { Accession } \\
\text { number }\end{array}$ & $\begin{array}{l}\text { Max } \\
\text { score }\end{array}$ & $\begin{array}{l}\text { Total } \\
\text { score }\end{array}$ & $\begin{array}{l}\text { Query } \\
\text { coverage }\end{array}$ & $\begin{array}{l}E \\
\text { value }\end{array}$ & $\begin{array}{l}\text { Per. } \\
\text { ident }\end{array}$ & $\begin{array}{l}\text { Accession } \\
\text { length }\end{array}$ & Resolution(Á) & Description \\
\hline 1. & 1EDG_A & 249 & 249 & $98 \%$ & $2 \mathrm{e}-79$ & $38.46 \%$ & 380 & 1.6 & $\begin{array}{l}\text { Ruminiclostridium } \\
\text { cellulolyticum }\end{array}$ \\
\hline 2. & 6MQ4_A & 294 & 294 & $95 \%$ & $1 \mathrm{e}-97$ & $40.61 \%$ & 353 & 1.4 & $\begin{array}{l}\text { Hungateiclostridium } \\
\text { cellulolyticum }\end{array}$ \\
\hline 3. & 4NF7_A & 217 & 217 & $94 \%$ & $2 e-67$ & $35.15 \%$ & 363 & 2.11 & Butyrivibrio proteoclasticus \\
\hline 4. & 4IM4_A & 293 & 293 & $93 \%$ & $4 e-97$ & $43.77 \%$ & 336 & 2.42 & $\begin{array}{l}\text { Hungateiclostridium } \\
\text { thermocellum }\end{array}$ \\
\hline 5. & 6GL2_A & 268 & 268 & $93 \%$ & $1 e-87$ & $40.29 \%$ & 337 & 1.96 & Zobellia galactanivorans \\
\hline 6 & 6WQP_A & 303 & 303 & $93 \%$ & $\begin{array}{l}5 e- \\
101\end{array}$ & $43.71 \%$ & 354 & 1.6 & $\begin{array}{l}\text { Ruminococcus } \\
\text { champanellensis }\end{array}$ \\
\hline 7. & 3NDY_A & 283 & 283 & $93 \%$ & $2 e-93$ & $43.31 \%$ & 345 & 2.1 & Clostridium cellulovorans \\
\hline 8. & 3AYR_A & 303 & 303 & $93 \%$ & $\begin{array}{l}1 e- \\
100\end{array}$ & $44.96 \%$ & 376 & 2 & Piromyces rhizinflatus \\
\hline 9. & 3AYS_A & 301 & 301 & $93 \%$ & $\begin{array}{l}9 e- \\
100\end{array}$ & $44.67 \%$ & 376 & 2.2 & Piromyces rhizinflatus \\
\hline 10. & 6Q11_A & 291 & 291 & $93 \%$ & $4 e-96$ & $43.87 \%$ & 357 & 1.35 & Clostridium longisporum \\
\hline
\end{tabular}

and relative (.) conservation regions. Also, query sequence (P2360) and 10 template sequences are aligned and the results of homology between them are shown in Figure S2.

The phylogenetic tree of amino acid sequences from different strains of Ruminococcus albus is shown in Fig. 1. It has been constructed with MEGA X, using maximum likelihood method based on the JTT matrix-based model. The bootstrap values at the node are higher than $90 \%$, indicating the robustness of the tree. There are two major groups present and one outgroup. The horizontal branches represent evolutionary lineages.

\section{Primary sequence analysis and subcellular localization}

The physicochemical properties details, like isoelectric point (pI), extinction coefficient, instability index (II),

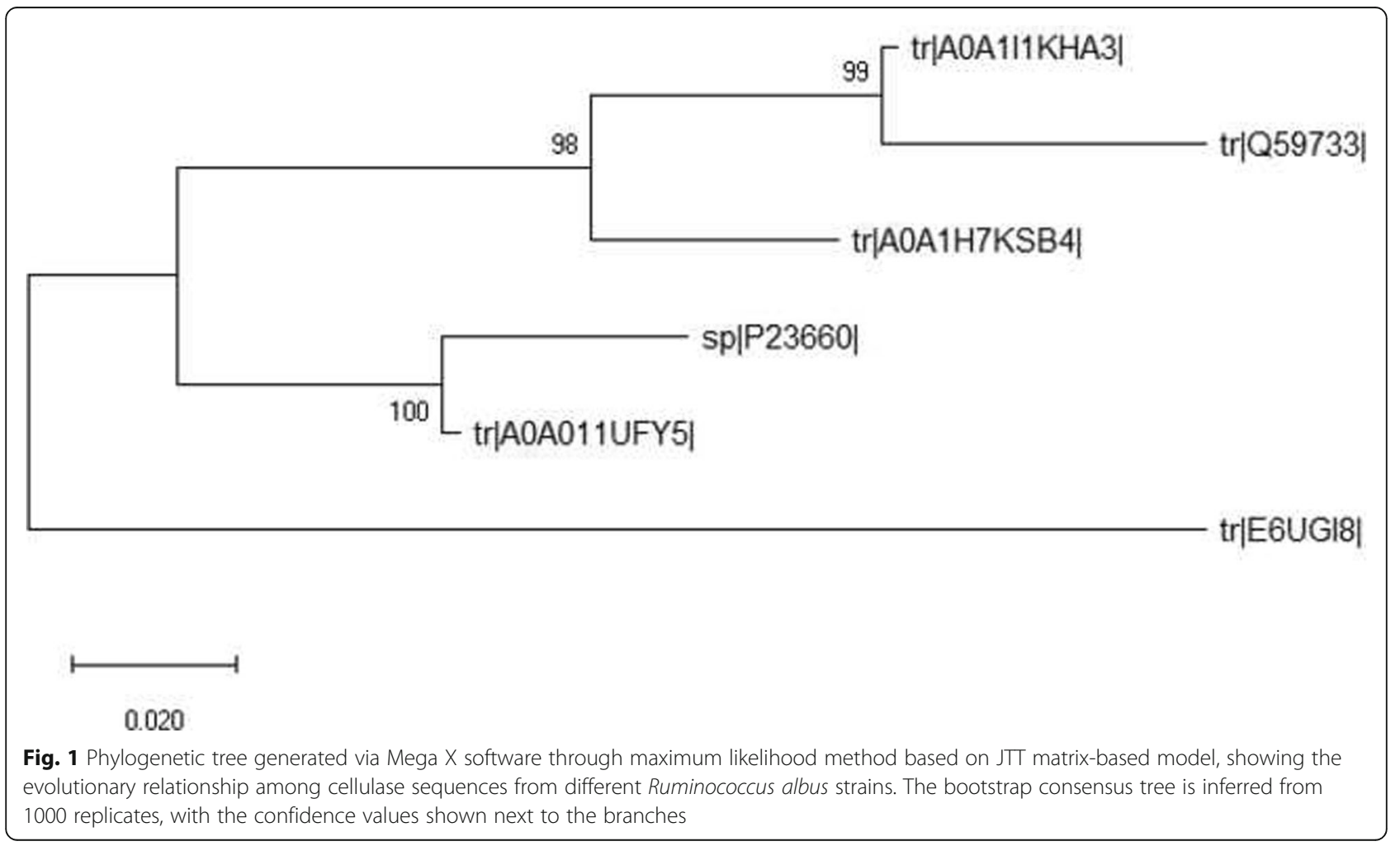


aliphatic index (AI), and Grand Average of Hydropathicity (GRAVY) for selected enzymes from different Ruminococcus albus strains are given in Table 3.

All sequences have similar values of the isoelectric point that lies between 4 and 4.5 which indicated the moderate acidic nature of the proteins. The extinction coefficients (EC) showed slight variation between cellulases of all strains. The values of instability index for all selected sequences were less than 40, indicating that the proteins are stable. The results indicated that $\mathrm{Ai}$ values ranged between 71.58 and 78.55 , which means that the proteins are thermostable. The GRAV $Y$ value represents the protein-water interactions. The GRAVY values were found to be negative and ranged between -0.552 and -0.649 , indicating the hydrophilic nature of the enzyme.

Possible disulfide linkages in the primary sequences are given in Table 3. In most of the cases, disulfide bridges were present.

A comparison of amino acid composition of cellulases from six strains of Ruminococcus albus is shown in Fig. 2. The $\mathrm{X}$-axis represents the amino acid composition, while the $\mathrm{Y}$-axis represents the percentage of each amino acid residue, while the color bars represent selected sequences.

The subcellular position of cellulase from Ruminococcus albus is predicted by different tools. CELLO predicted that the enzyme was extracellular with the highest reliability of 0.864 . Also, PSLpred predicted the protein sequence as extracellular with a reliability index of 3.294. The subcellular position of cellulase from Ruminococcus albus is predicted by using TMHMM Server, v.2.0. Summary outputs revealed that the enzyme has no transmembrane helix (Figure S3).

\section{Secondary structure topology and signal peptide prediction}

The secondary structure of selected cellulase sequences was estimated using SOPMA tools. The percentage of alpha helix, extended strand, beta turn, and random coils in these sequences from different Ruminococcus albus and from 10 template sequences are shown in Table 4 . From these results, it is observed that random coils are dominant in all sequences, followed by alpha helix and extended strand. The query sequence displayed the lowest percentage of random coils (42.31) compared with other sequences and the highest value of beta turn (5.77). The secondary structure map and a graphical representation of query sequence (P23660) predicted by PSIPRED [20] are shown in Fig. 3a and b. A graphical presentation of query and template secondary structure alignment is shown in Figure S4.

TMHMM and TOPCONS revealed that the protein has no transmembrane helixes and is present outside the membrane part of the cell (Figure S3). SignalP suggests no signal peptide.

\section{D Structure prediction using homology modeling, model evaluation, and refinement}

The 3D models of cellulase from Ruminococcus albus (P23660) were gained by different protein structure homology model building programs: SWISS-MODEL Homology Modelling, Raptor X, $\mathrm{PS}^{2}-\mathrm{V} 2$, Phyre 2, and Lomets.

Phyre2 suggested the 1EDG_A template as one of the best homologous templates for a possible 3D cellulase protein structure, with 100\% confidence and 97\% coverage. The same template was suggested also by $\mathrm{PS}^{2} \mathrm{~V} 2$, with alignment at $98 \%, e$ value $2.6 \mathrm{e}-18$, and $37.93 \%$ identity. Submission of cellulase to the Swiss Model server generated one protein structure model, where the best template was 3AYS_A showing $44.67 \%$ sequence identity, resolution 2.20 , sequence similarity 0.43 , and coverage 0.93 . The best model predicted by Lomets was generated using 3AYR_A as a template with 1550 Norm Zscore. RaptorX suggested 6Q1I_A as the best template for the 3D cellulase structure, with a $p$ value $2.22 \mathrm{e}-09$. All models obtained by these programs were refined by ModRefiner, to refine the protein structure closer to the native.

The initial and refined models were taken for validation analyses by PROCHECK [29]. RAMPAGE validates 3D models by plotting the Ramachandran plot. In the Ramachandran plot of all models, the percent residues were located in favored, allowed, and disallowed. The Ramachandran plot of each model is compared, and the results are shown in Table 5 . The best model was generated with Raptor X, with PDB ID: 6Q1I, as a template.

Table 3 Physicochemical properties of selected proteins, from different strains of Ruminococcus albus

\begin{tabular}{llllllr}
\hline No. & Accession no. & Theoretical pl & Extincion coefficient & Instability index & Aliphatic index & GRAVY \\
\hline 1. & P23660 & 4.53 & 95465 & 25.73 & 73.96 & -0.601 \\
2. & A0A011UFY5 & 4.39 & 95465 & 29.13 & 71.58 & -0.594 \\
3. & A0A1H7KSB4 & 4.40 & 97080 & 26.53 & 72.18 & -0.585 \\
4. & A0A111KHA3 & 4.37 & 95590 & 28.89 & 73.21 & -0.552 \\
5. & Q59733 & 4.44 & 90090 & 28.85 & 73.28 & -0.556 \\
6. & E6UGI8 & 4.39 & 92610 & 33.92 & 78.55 & -0.649 \\
\hline
\end{tabular}




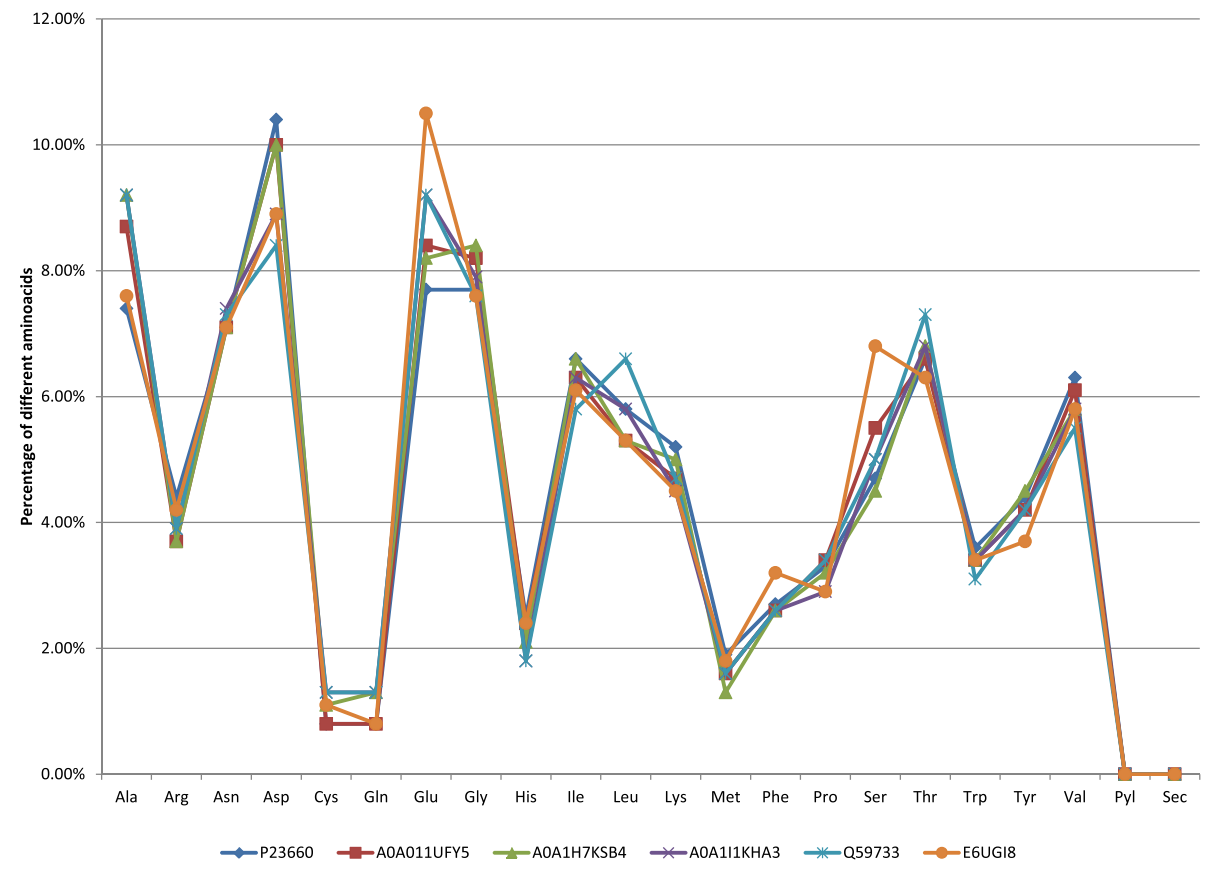

Fig. 2 Graphical representation of the amino acid composition of selected cellulase sequences

Table 4 Predicted secondary structure content and disulfide bridges from 6 cellulase proteins of Ruminococcus albus strains and from 10 selected template structures

\begin{tabular}{|c|c|c|c|c|c|c|}
\hline No. & Accession no. & Alpha helix & Extended strand & Beta turn & Random coil & Disulfide bridge prediction \\
\hline \multicolumn{7}{|c|}{ Cellulase protein } \\
\hline 1. & P23660 (Target) & 37.91 & 14.01 & 5.77 & 42.31 & None \\
\hline 2. & A0A011UFY5 & 37.05 & 12.11 & 4.60 & 46.25 & $23-398$ \\
\hline 3. & A0A1H7KSB4 & 36.80 & 12.59 & 4.84 & 45.76 & $23-362$ \\
\hline 4. & A0A $111 \mathrm{KHA} 3$ & 40.44 & 12.11 & 4.36 & 43.10 & $23-398$ \\
\hline 5. & Q59733 & 40.34 & 12.08 & 4.11 & 43.48 & 23-398 \\
\hline 6. & E6UGI8 & 38.78 & 13.41 & 4.88 & 42.93 & $23-375$ \\
\hline \multicolumn{7}{|c|}{ Templates } \\
\hline 7. & 1EDG_A & 35.00 & 12.63 & 5.00 & 47.37 & None \\
\hline 8. & 6MQ4_A & 35.98 & 15.01 & 5.10 & 43.91 & None \\
\hline 9. & 4NF7_A & 37.47 & 13.50 & 4.68 & 44.35 & $117-221$ \\
\hline 10. & 4IM4_A & 37.80 & 15.18 & 3.87 & 43.15 & None \\
\hline 11. & 6GL2_A & 36.20 & 15.43 & 4.45 & 43.92 & 235-304 \\
\hline 12. & 6WQP_A & 35.59 & 14.12 & 4.24 & 46.05 & $207-217$ \\
\hline 13. & 3NDY_A & 36.81 & 13.91 & 4.93 & 44.35 & None \\
\hline 14. & 3AYR_A & 39.89 & 13.03 & 5.05 & 42.02 & None \\
\hline 15. & 3AYS_A & 35.11 & 15.69 & 6.12 & 43.09 & $41-221$ \\
\hline 16. & 6Q11_A & 36.41 & 14.01 & 4.76 & 44.82 & None \\
\hline 17. & 1EDG_A & 35.00 & 12.63 & 5.00 & 47.37 & None \\
\hline
\end{tabular}


a

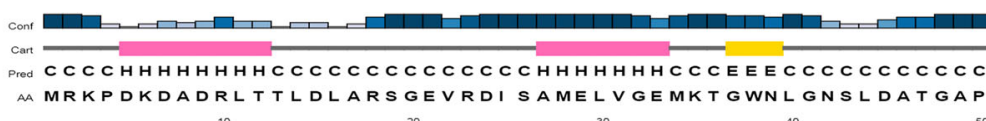

AA MRKPDKDADRLTTLDLARSGEVRDI SAMELVGEMKTGWNLGNSLDATGAP$$
10
$$

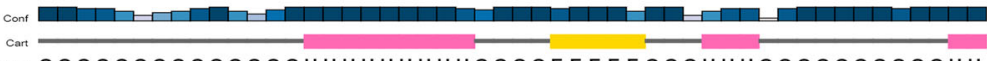

Pred CCCCCCCCCCCCCCHHHHHHHHHCCCCEEEEECCCHHHCCCCCCCCCCHH

M ONASEVNWONPKTTKEMI DAVYNKGEDVI RI PVT WGGHVGDAPDYKIDDE

so

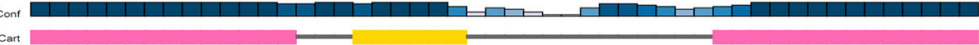

Pred HHHHHHHHHHHHCCCEEEEECCCCCCCCCCCCCHHHHHHHHHHHH

AA WI ARVQEVVNYAYDDGAYVI I NSHHEEDWRI PDNEHI DAVDEKTAAI WKQ

110

120

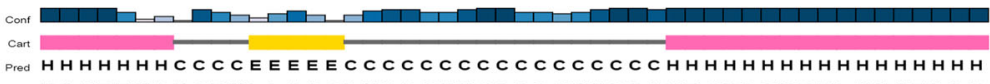

rod HHHHHHHCCCCEEEEECCCCCCCCCCCCCCCCCHHHHHHHHHHHHHHHHH
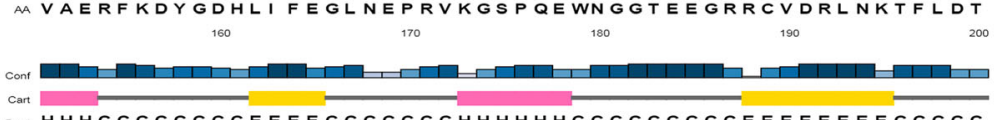

Proc HHHCCCCCCCCEEEECCCCCCCHHHHHHCCCCCCCCCEEEEEEEECCCCC

AA VRATGGNNEKRLLLMTTYASSSMSNVI KDTAI PEDDHI GFSI HAYTPYAF

210

220

240

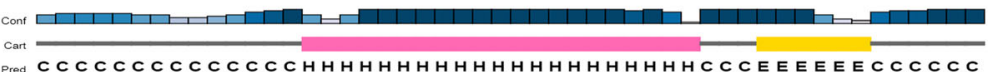

Pred $C$ C C C C C C C C C C C H H H H H H H H H H H H H H H C C EEEEEECCCCCC

AA TYNANADWELFHWDDSHDGELVSLMTNLKENYLDKDI PVI I TEYGAVNKD

260

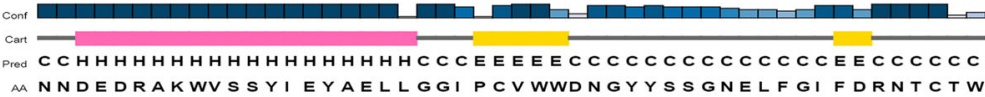

Prod CCHHHHAHHHHHHHHHHHHHCC CEEEEECCCCCCCCCCCCCCEECCCCCC

310

20

330

340

350

Cont

AA FTDTVTDAI I ENAK

Legend:

Strand
Helix
Coil

360

370



b 10 20 $30 \quad 40$ 50

MRK P D K D A D RLLTTLDLARSGEVRDISAMELVGE MKTGWNLGNSLDATGAP 50 G N A S E V N W G N P K T T K K E M I D A V Y N N K G F D V I R I I P V T W G G H V G D A P D Y K I D D E 100

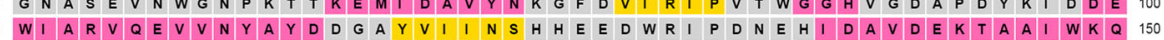

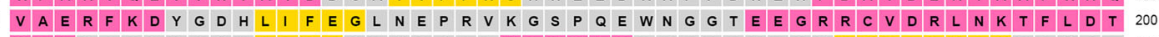
V R A T G G N N E K R L L L M T T Y A S S S M S N V I K D T A I P E D D H I G F S I H A Y T P Y A F 250 T Y N A N A D WE L F HWD D S H D G E L V S L M T N L K E N Y L D K D I P V I I T N N D E D R A K K WV S S Y I E Y A E L L G G I P C V WWDNG Y Y S S GNELF G I F D R N T C T W 350

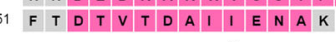

10

30

40

\begin{tabular}{l|lll}
$\square$ Strand & Helix & Coil & $\square$ Disordered \\
$\square$ Disordered, protein binding & Putative Domain Boundary & Membrane Interaction & Transmembrane Helix \\
Extracellular & Re-entrant Helix & Cytoplasmic & Signal Peptide
\end{tabular}

Fig. 3 Secondary structure map (a) and graphical representation of the predicted secondary structures present within the protein P23660 (b) attained by PSIPRED (The pink blocks represent the alpha helices; the yellow blocks represent beta strands, and the black thread-like structures were the coils. The confidence of prediction observed throughout the predicted secondary structure was quite high, indicating high reliability of the prediction

The percentage of favored regions is $88.5 \%$ and with the minimum percent of the disallowed region (0); meanwhile, the refined model of Raptor X (Fig. 4) showed the highest percentage of the favored region (90.1), which implies the characteristics of a good quality model.

\section{Structure alignments}

The final refined 3D protein structure model was superimposed with the structure of the template 6Q1I_A. The outputs are shown in Fig. 5 and indicate geometrical and structural similarity. The calculated $\mathrm{z}$ score was 53 and RMSD was 1.1. Most query and template structures are matched in tertiary structure alignment.

\section{Functional analysis}

Two functional motifs were detected, which were found to be a member of the glycoside hydrolase family (Figure S5).

Functional analysis revealed five potential interacting partners of cellulase in the protein interaction network 
Table 5 The Ramachandran plot structure validation of original and refined structures

\begin{tabular}{llllll}
\hline Model & & Favored region (\%) & Additional allowed region (\%) & Generously allowed region (\%) & Disallowed region (\%) \\
\hline \multirow{2}{*}{ Swiss model } & Original & 86.4 & 12.6 & 0.7 & 0.3 \\
& Refined & 87.7 & 11.3 & 0.3 & 0.7 \\
\multirow{2}{*}{ Raptor X } & Original & 88.5 & 10.2 & 1.2 & 0.0 \\
& Refined & 90.1 & 9.0 & 0.6 & 0.3 \\
\multirow{2}{*}{ PS $^{2}-$ V2 } & Original & 85.4 & 12.7 & 1.6 & 0.3 \\
& Refined & 90.4 & 7.8 & 0.6 & 1.2 \\
\multirow{2}{*}{ LOMETS } & Original & 83.5 & 13.0 & 2.5 & 0.9 \\
& Refined & 90.1 & 7.8 & 1.2 & 0.9 \\
\multirow{2}{*}{ Phyre } & Original & 82.6 & 12.7 & 2.5 & 2.2 \\
& Refined & 88.8 & 9.3 & 1.2 & 0.6 \\
\hline
\end{tabular}

as resolved by STRING analysis (Fig. 6). The query protein Rumal have five closest interacting protein with cellulase, endoglucanase, and glycosyltransferase activity. The STRING database analysis depicted that the protein-protein interaction (PPI) network is comprised of 6 nodes connected with 14 different edges. The expected number of edges was 6 , while the average node degree score was 4.67 which means that one node had at least 4.67 interacting nodes. The average local clustering coefficient was 0.933 and PPI enrichment $p$ value was observed as 0.00152 . Protein-protein interaction (PPI) networks showed that cellulase interacted with 5 other proteins in a very high score of confidence. The closest interacting protein was Rumal_2606 (Cellulose 1.4 beta cellobiosidase), with the shortest node with a score of 0.973. It belongs to the glycoside hydrolase family protein. Then Rumal_1050 (Endoglucanase) had a score of 0.968 belonging to the glycoside hydrolase family 9 . Rumal 2777 (Endoglucanase) is part of the glycoside hydrolase family 5 and had a score of 0.946 , Rumal_2448 (cellulase) is part of the glycoside hydrolase family 9 and had a score of 0.943 , and finally, Rumal_0187, with glycosyltransferase function had a score of 0.914 .

Ligand binding sites determined by the use of COFACTOR software indicate the conserved residues with the highest Cscore, which is the confidence score of the predicted binding site. Cscore for the predicted binding site is 0.69 . The residues in the predicted binding site are as follow: 42, 58, 124, 125, 168, 245, 293, 328, 330, and 338. BS-score which is a measure of local similarity (sequence \& structure) between template binding site and predicted binding site in the query structure was



Fig. 4 Predicted 3D structure of cellulase from Ruminococcus albus provided by Raptor $X$ and refined by ModRefiner 




Fig. 5 Dali 3D structure alignment between query sequence P23660 (green) and template 6Q11 (brown)

1.67 (BS-score $>1$ ) representing a significant local match between the predicted and template binding site (Fig. 7).

GHECOM server finds five pockets on protein surfaces using mathematical morphology, and the results of pocket structure based on pocketness color are shown in Fig. 8. The pockets contribute to the formation of binding sites and active sites of protein [30,31].

The pockets predicted by CASTp are shown in Fig. 9, where different cavities are shown in different colors, based on area and volume size; the most important is illustrated in red color. The largest pocket has an area of 370.310 and a volume of 324.097 amino acids. The second pocket has an area of 63.733 and a volume of 21.367 amino acids.

The probability of residue forming a binding site and residue depth plot and a 3D rendition of the cavity prediction is shown in Fig. 10.

\section{Discussion}

Cellulases are complex enzymes that are produced by different organisms. Cellulases play an important role in different areas of industry and in animal feeding to enhance the digestibility of fiber-rich roughage fed to ruminants [32]. Two different cellulolytic enzymes from black goat rumen have been characterized [33, 34]. Also, an in silico analysis of cellulases from Bacillus sp. is previously done [14], but from Ruminococcus albus is not analyzed earlier in detail by bioinformatic tools.
According to Sefid et al. [31], the use of bioinformatics tools is a compelling strategy to close the gap between the number of protein sequences and the $3 \mathrm{D}$ protein structure. Computational tools are increasingly used to focus the search in sequence space, enhancing the efficiency of laboratory evolution [35]. Adyaman et al. [10] admit that in silico protein modeling is comparatively cheaper and faster than experimental determination methods.

Consequently, in silico analysis of protein structure is one of the very useful methods for studying the structural and functional aspects of the protein [8]. In silico analysis of proteins has played a great contribution recently in the field of computational biology illustrating the structural and functional aspects of proteins [36-39].

The present study has considered the phylogenetic, structural, and functional analysis of cellulase from Ruminococcus albus. The phylogeny of cellulases from 6 selected strains indicates that there are two groups in these strains. The tree is of high reliability since the bootstrap values are $98-100 \%$.

This study has demonstrated several physicochemical characteristics which determine the uniqueness of a molecule. According to Mohanta et al. [40], the isoelectric or isoionic point of a protein is the $\mathrm{pH}$ at which a protein carries no net electrical charge and is considered neutral. Prediction of pI is essential in the development of buffer systems for purification and isoelectric focusing [41]. A protein is considered as alkaline in nature if the 


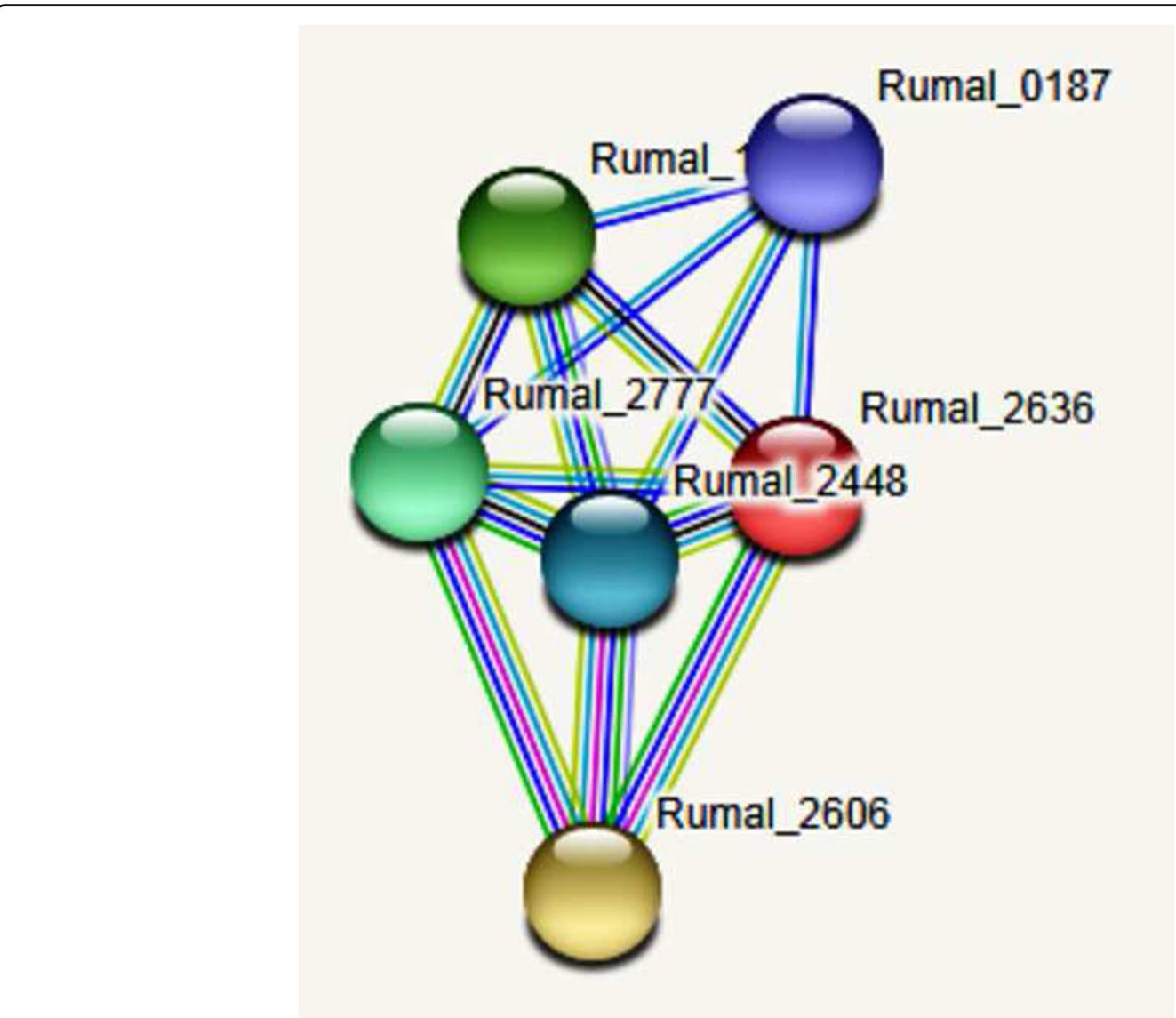

Fig. 6 Protein-protein interaction map for the cellulase of Ruminococcus albus

pI value is greater than 7 , and acidic when the value is below 7. In this study, the pI values of all selected cellulase sequences ranged between 4.39 and 4.53 suggesting a moderately acidic nature of these cellulases, like in some Bacillus sp. [14], but the cellulases from Bacillus subtilis were alkaline [14]. The instability index (II) indicates protein stability. Proteins with II higher than 40 are referred as unstable [42]. The instability indices of all selected cellulase sequences from different Ruminoccocus albus were less than 40; therefore, the enzymes are considered stable. Also, the cellulases from different Bacillus sp. were found to be stable [14]. The aliphatic index is the relative volume of the protein occupied by the aliphatic amino acids in the side chain [43] and plays role in protein thermal stability. The values of aliphatic indices were more than 71, indicating a thermostable nature of all enzymes. This is in line with the fact that Ruminococcus albus is one of the few organisms that ferment cellulose to form ethanol at mesophilic temperatures in vitro [44]. The thermostable behavior of the protein is suitable for the dairy industry [37], in the sugar industries, where high temperatures are required for efficient extraction. The hydrophobic or hydrophilic character of cellulases is analyzed with the GRAVY score. GRAVY values were found to be negative, indicating that the proteins are nonpolar and hydrophilic. The acidic and stable nature of these enzymes allows them to survive in the moderate acidic environment of the rumen of ruminant species. The $\mathrm{pH}$ values 5.8 to 6.4 are considered as an optimal $\mathrm{pH}$ range for the activity of cellulolytic bacteria, including $R$. albus, and cellulases. If the $\mathrm{pH}$ value in the rumen felt below 5.5, the activity of cellulolytic and consequently fiber digestion is strongly reduced. On the contrary, in this $\mathrm{pH}$ range, the activity of mainly starch-fermenting taxa such as Prevotella is very high. On this basis, several authors (among them Zebeli et al. [5]) recommend that if the $\mathrm{pH}$ value remains below 5.8 for an interval of more than 5-6 h during the day, this is a sign of subacute ruminal acidosis in dairy cows (SARA).

The selected cellulase sequences from different strains of Ruminococcus albus have similar variations in amino acid compositions, as can be seen in Fig. 3. This composition implies a similar function and hydrolyses the same substrate. The prediction of protein secondary structures from sequences is considered as a bridge between the primary sequences and tertiary structure prediction [45]. Based on secondary structure prediction, it 


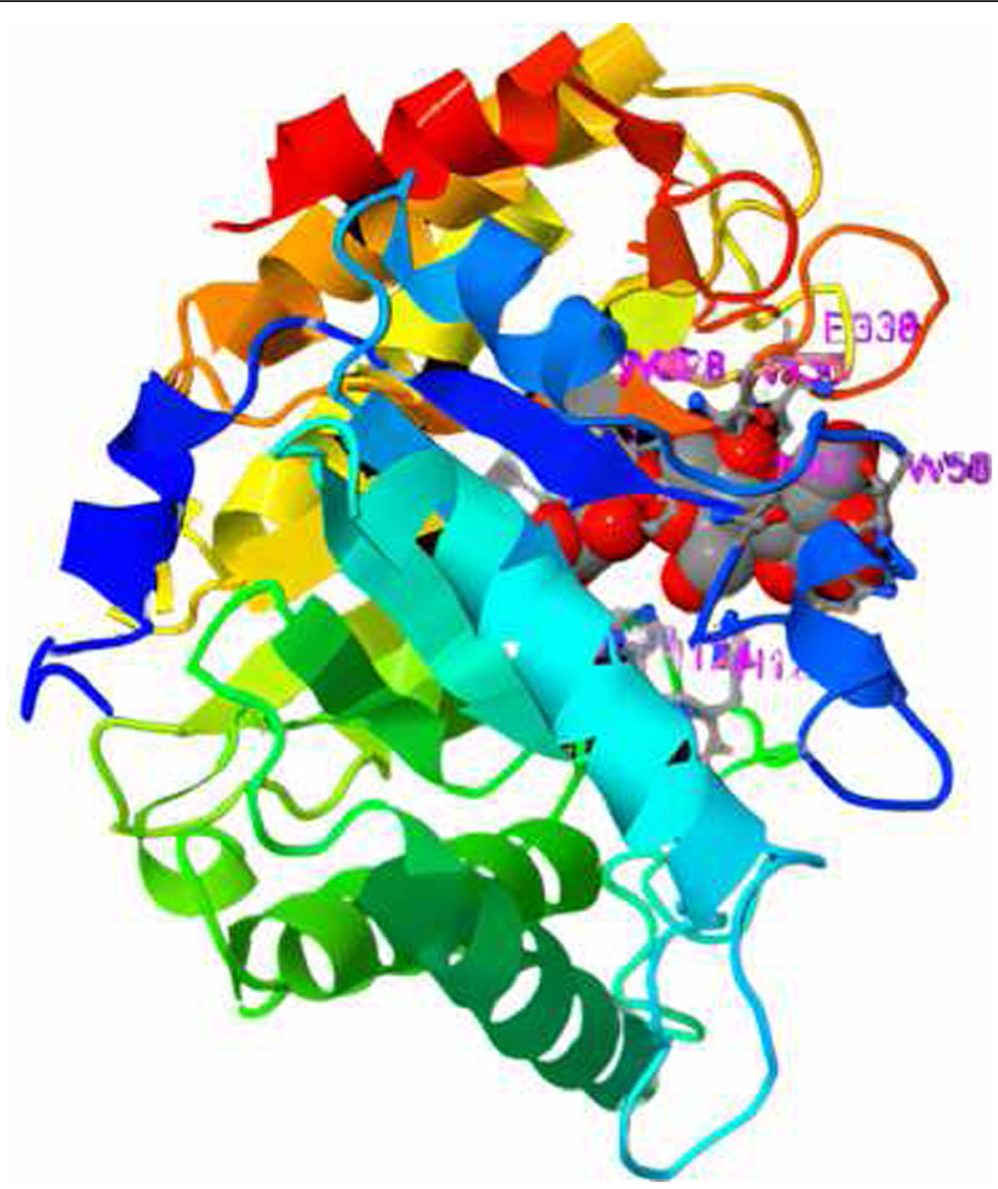

Fig. 7 Predicted ligand binding sites of cellulase from Ruminococcus albus

was observed that cellulases from all strains were classified in random coils and alpha helix. There was no disordered protein binding site present, and proteins are not unfolded. The high percentage of the alpha helix structure indicates that the enzymes are thermostable, which is in concordance with the high values of the aliphatic index. The cysteine residues are very important because they may take part in the formation of disulfide bonds between various parts of the protein. Disulfide bonds play an important role in folding and stabilizing

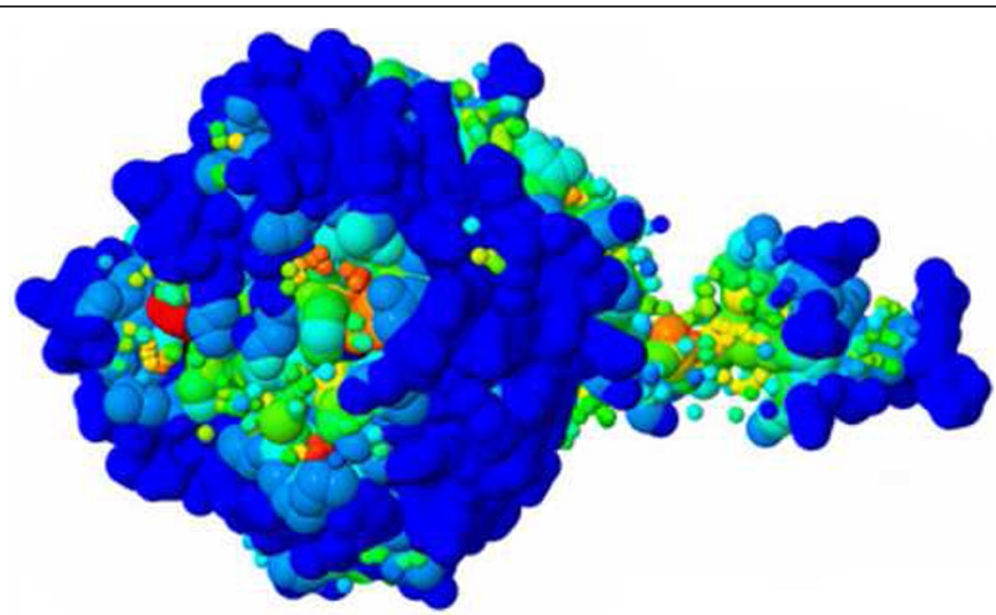

Fig. 8 GHECOM results, Jmol view of pocket structure based on pocketness color 


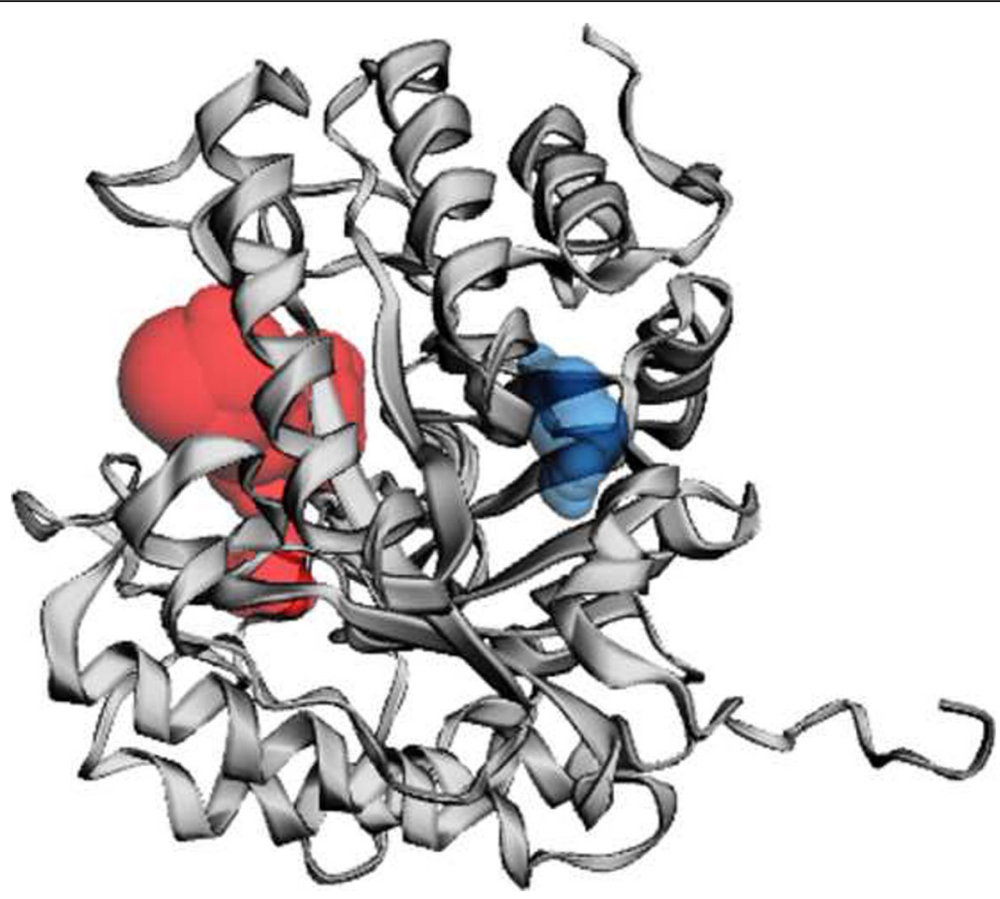

Fig. 9 CastP results showing surface accessible pockets as well as interior inaccessible cavities

the unfolded form of the protein by lowering the entropy [12]. Lugani et al. [14] found that alpha helix was dominant in Bacillus pumilus, whereas extended strand and the random coil were observed to be dominant in Bacillus subtilis and Paenibacillus polymyxa. The enzyme was extracellular, and this was supported also by the TMHMM tool which indicates no transmembrane domain present in the protein.

Prediction of 3D model of a protein by in silico analysis is a highly challenging aspect to corroborate the data obtained from the NMR or X-ray crystallographybased methods [37]. The query sequence (P23660) was blasted against PDB to find the best template. The selection criteria were lower $E$ value and higher query coverage and maximum identity. The accuracy of the predicted model depends on the degree of sequence similarity. In our study, the query and template sequences shared $39.94-44.96 \%$ identity, which means that more than $80 \%$ of the C-atoms can be expected to be within $3.5 \AA$ of their true position [9].

All models provided by different servers were evaluated. The best model of the tertiary structure was obtained by Raptor X where 6Q1I, which is endoglucanase from Clostridium longisporum, has been used as a structural template. Model refinement is important to improve the quality of predicted models. The refinement of the predicted 3D protein model is carried out by ModRefiner. It is a crucial step in bringing the models closer to experimental accuracy for further computational studies [10]. The Ramachandran plot for the predicted model showed that more than $90 \%$ of the residues are in the favored region, implying a good quality model [46].

The alignment of the predicted model and template structure (6Q1I) is applied by Dali software to evaluate the similarity between structures. The value of RMSD indicates the degree to which both three-dimensional structures are similar. The smaller the value of RMSD, the more similar the structures are. Thus, the predicted model was confirmed to be reliable and accurate. The results confirmed the reliability of the structure predicted by RaptorX. Therefore this theoretical structure was deposited at PMDB database and the accession number of the model is PM0083494.

\section{Conclusions}

Cellulases are complex enzymes that are produced by many microorganisms including fungi and bacteria that degrade cellulose. There are a lot of areas of industry, including the animal feed industry and ruminant feeding, where microbial cellulases have a great application. Therefore in silico analysis of the physicochemical features of a protein is very important to get a theoretical overview of the enzyme. This study presents the first reported structural analysis of cellulases from Ruminococcus albus. Phylogenetic analysis was performed and indicated two major groups in cellulases from different Ruminococcus albus bacterial strains. From this study, it was found that cellulase is an extracellular, acidic, hydrophilic, and thermostable enzyme with a molecular weight of about $41 \mathrm{KDA}$. These properties help them to 


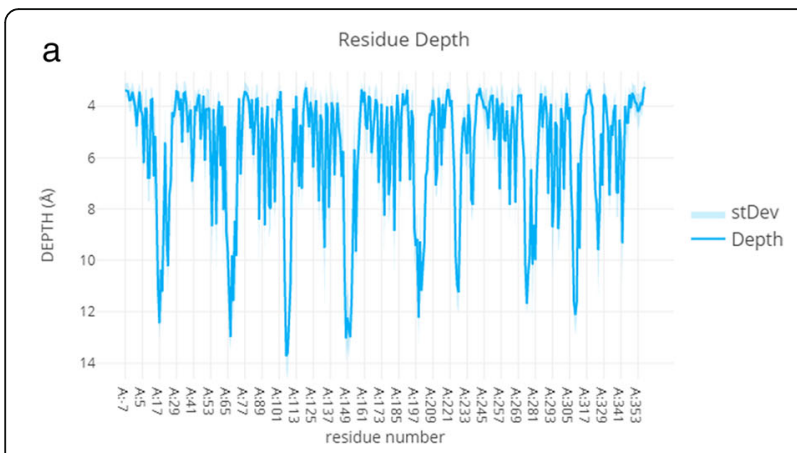

b Probability of Residue Formaing a Binding Site

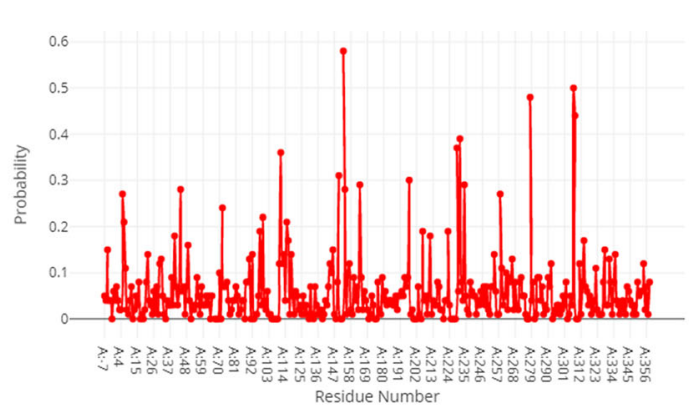

C

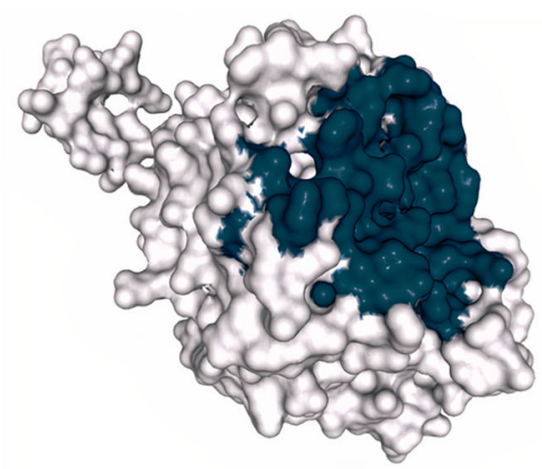

Fig. 10 Residue depth plot (a), probability of residue forming a binding site (b), and a 3D rendition of the cavity prediction (c)

survive in the acidic rumen environment. The study provides the characteristics of secondary structures, indicating that cellulase is composed mostly of random coil followed by alpha helix and extended strand. This protein showed two functional motifs belonging to the glycoside hydrolase family. The structure evaluation and $3 \mathrm{D}$ alignment show that the best 3D cellulase protein model was obtained by RaptorX homology modeling program based on the 6Q1I template.

Verification of predicted 3D model by Ramachandran plot presented that most of the residues are in the allowed or favored regions of the plot. Also, the alignment analysis of this model with the template (6Q1I) supported the good quality of the predicted model, which was submitted in the PMDB database. This study gives a piece of theoretical information about the structural and functional properties of cellulase from
Ruminococcus albus and may help for further investigations regarding the potential application of cellulase in the industry.

\section{Abbreviations \\ Al: Aliphatic index; pl: Isoelectric point; II: Instability index; GRAVY: Grand average of hydropathicity; EC: Extinction coefficient; PPI: Protein-protein interaction; SARA: Subacute ruminal acidosis in dairy cows; PDB: Protein Data Bank; SPs: Signal peptides; RMSD: Root mean square deviation}

\section{Supplementary Information}

The online version contains supplementary material available at https://doi. org/10.1186/s43141-021-00162-x

Additional file 1 : Fig. S1. Multiple Sequence Alignment of cellulase sequences from different Ruminoccocus albus strains, generated by the use of Clustal Omega. Black shaded regions indicate similar residues.

Additional file $\mathbf{2}$ : Fig. S2. Representation of homology between the query sequence (P23660) and the selected templates from different species. Conserved residues are highlighted from blue to red colors.

Additional file $\mathbf{3}$ : Fig. S3. Prediction of subcellular localization of cellulase from Ruminococcus albus by TMHMM server.

Additional file 4 : Fig. S4. Representation of secondary structure alignment between the query sequence (P23660) and the selected templates from different species.

Additional file $\mathbf{5}$ : Fig. S5. Result of motif finder showing two functional motifs for the cellulase of Ruminococcus albus.

\section{Acknowledgements}

Not applicable.

\section{Authors' contributions}

$\mathrm{AH}$ has designed the work, analyzed data (primary, secondary, and tertiary structures) and drafted the work; MT has interpreted the data and revised the manuscript; ES analyzed (functional analysis) and interpreted the data. The authors have read the manuscript and approved it for publication in the Journal of Genetic Engineering and Biotechnology.

\section{Authors' information}

Prof. Anila Hoda*: Corresponding author: Agricultural University of Tirana, Department of Animal Production; Koder Kamez, 1029, Tirana, Albania; email ahoda@ubt.edu.al; https://orcid.org/0000-0003-0906-2550. The research area is Molecular genetics, Biotechnology, Bioinformatics.

Prof. Myqerem Tafaj: Agricultural University of Tirana, Department of Animal Production; Koder Kamez, 1029, Tirana, Albania, tel: 00355692420868; email mtafaj@ubt.edu.al. The research area is: Nutrition physiology of animal; Ruminant Nutrition; Rumen digestion and ecosystem; Applied animal feeding; Dairy and beef production.

Prof. Enkelejda Sallaku: Agricultural University of Tirana, Department of Animal Production; Koder Kamez, 1029, Tirana, Albania; email enka. sallaku@ubt.edu.al. The research area is: Nutrition physiology of animal; Ruminant Nutrition; Dairy and beef production.

\section{Funding}

This research received no specific grant from any funding agency in the public, commercial, or not-for-profit sectors.

Availability of data and materials

All data generated or analyzed during this study are included in this published article.

\section{Declarations}

Ethics approval and consent to participate

This article does not contain any studies with human participants or animals performed by any of the authors. 


\section{Consent for publication}

Not applicable.

\section{Competing interests}

The authors declare that they have no competing interests.

Received: 15 December 2020 Accepted: 7 April 2021

Published online: 19 April 2021

\section{References}

1. Henderson G, Cox F, Ganesh S, Jonker A, Young W, Abecia L, Angarita E, Aravena P, Arenas GN, Ariza C et al (2015) Rumen microbial community composition varies with diet and host, but a core microbiome is found across a wide geographical range. Sci Rep 5(1):14567. https://doi.org/10.103 8/srep14567

2. Krause DO, Denman SE, Mackie Rl, Morrison M, Rae AL, Attwood GT, McSweeney CS (2003) Opportunities to improve fiber degradation in the rumen: microbiology, ecology, and genomics. FEMS Microbiol Rev 27(5): 663-693. https://doi.org/10.1016/S0168-6445(03)00072-X

3. Suen G, Stevenson DM, Bruce DC, Chertkov O, Copeland A, Cheng J-F, Detter C, Detter JC, Goodwin LA, Han CS, et al. (2011) Complete genome of the cellulolytic ruminal bacterium Ruminococcus albus 7.

4. Ölschläger V (2007) Molekularbiologische und enzymatische Untersuchungen zum Einfluss von Partikellänge und Konzentratanteil auf Parameter der fibrolytischen Pansenverdauung. PhD Diss. Universität Hohenheim, Hohenheim, Germany. Cuvillier Verlag

5. Zebeli Q, Tafaj M, Junck B, Olschlager V, Ametaj BN, Drochner W (2008) Evaluation of the response of ruminal fermentation and activities of nonstarch polysaccharide-degrading enzymes to a particle length of corn silage in dairy cows. J Dairy Sci 91(6):2388-2398. https://doi.org/10.3168/ jds.2007-0810

6. Cersosimo LM (2017) Rumen microbial ecology and rumen-derived fatty acids: determinants of and relationship to dairy cow production performance

7. Islam F, Roy N (2018) Screening, purification and characterization of cellulase from cellulase producing bacteria in molasses. BMC Res Notes 11 $1-6$

8. Santhoshkumar R, Yusuf A (2020) In silico structural modeling and analysis of physicochemical properties of curcumin synthase (CURS1, CURS2, and CURS3) proteins of Curcuma longa. J Genet Eng Biotechnol 18:1-9

9. Sefid F, Rasooli I (2013) Jahangiri A (2013) In silico determination and validation of baumannii acinetobactin utilization a structure and ligandbinding site. BioMed Res Int 2013:1-14. https://doi.org/10.1155/2013/172784

10. Adiyaman $R$, McGuffin $L J$ (2019) Methods for the refinement of protein structure 3D models. Int J Mol Sci 20(9):2301. https://doi.org/10.3390/ijms2 0092301

11. Mohan C, Santos Junior CD, Chandra S (2020) In silico characterization and homology modeling of a pathogenesis-related protein from Saccharum arundinaceum. Arch Phytopathol Plant Prot 53(5-6):199-216. https://doi. org/10.1080/03235408.2020.1736739

12. Hasan R, Rony MNH, Ahmed R (2021) In silico characterization and structural modeling of bacterial metalloprotease of family M4. J Genet Eng Biotechnol 19:1-20

13. Mustafa MI, Murshed NS, Abdelmoneim AH, Abdelmageed MI, Elfadol NM, Makhawi AM (2020) Extensive in silico analysis of ATL1 gene: discovered five mutations that may cause hereditary spastic paraplegia type $3 \mathrm{~A}$. Scientifica 2020:1-13. https://doi.org/10.1155/2020/8329286

14. Lugani $Y$, Sooch BS (2017) In silico characterization of cellulases from genus Bacillus. Int J Curr Res Rev 9:30-37

15. Jones DT, Taylor WR, Thornton JM (1992) The rapid generation of mutation data matrices from protein sequences. Bioinformatics 8(3):275-282. https:// doi.org/10.1093/bioinformatics/8.3.275

16. Kumar S, Stecher G, Li M, Knyaz C, Tamura K (2018) MEGA X: molecular evolutionary genetics analysis across computing platforms. Mol Biol Evol 35(6):1547-1549. https://doi.org/10.1093/molbev/msy096

17. Gasteiger E, Hoogland C, Gattiker A, Duvaud S, Wilkins MR, Appel RD, Bairoch A (2005) Protein identification and analysis tools on the ExPASy Server. In: Walker JM (ed) The proteomics protocols handbook. Humana, Totowa. pp. 571-607

18. Yu C-S, Cheng C-W, Su W-C, Chang K-C, Huang S-W, Hwang J-K, Lu C-H (2014) CELLO2GO: a web server for protein subCELlular LOcalization prediction with functional gene ontology annotation. PloS one 9(6):e99368. https://doi.org/10.1371/journal.pone.0099368

19. Krogh A, Larsson B, Von Heijne G, Sonnhammer EL (2001) Predicting transmembrane protein topology with a hidden Markov model: application to complete genomes. J Mol Biol 305(3):567-580. https://doi.org/10.1006/ jmbi.2000.4315

20. McGuffin LJ, Bryson K, Jones DT (2000) The PSIPRED protein structure prediction server. Bioinformatics 16(4):404-405. https://doi.org/10.1093/ bioinformatics/16.4.404

21. Tsirigos KD, Peters C, Shu N, Kall L, Elofsson A (2015) The TOPCONS web server for consensus prediction of membrane protein topology and signal peptides. Nucleic Acids Res 43(W1):W401-W407. https://doi.org/10.1093/nar/gkv485

22. Petersen TN, Brunak S, Von Heijne G, Nielsen H (2011) SignalP 4.0: discriminating signal peptides from transmembrane regions. Nat Methods 8(10):785-786. https://doi.org/10.1038/nmeth.1701

23. Kelley LA, Mezulis S, Yates CM, Wass MN, Sternberg MJ (2015) The Phyre2 web portal for protein modeling, prediction and analysis. Nat Protoc 10(6): 845-858. https://doi.org/10.1038/nprot.2015.053

24. Chen C-C, Hwang J-K, Yang J-M (2009) 2-v2: template-based protein structure prediction server. Bmc Bioinformatics 10(1):366. https://doi.org/1 0.1186/1471-2105-10-366

25. Wu S, Zhang Y (2007) LOMETS: a local meta-threading-server for protein structure prediction. Nucleic Acids Res 35(10):3375-3382. https://doi.org/10.1 093/nar/gkm251

26. Holm L (2020) DALI and the persistence of protein shape. Protein Sci 29(1): 128-140. https://doi.org/10.1002/pro.3749

27. Hooda V (2011) Physicochemical, functional and structural characterization of wheat germin using in silico methods. Curr Res J Biol Sci 3:35-41

28. Szklarczyk D, Franceschini A, Wyder S, Forslund K, Heller D, Huerta-Cepas J, Simonovic M, Roth A, Santos A, Tsafou KP, others (2015) STRING v10: protein-protein interaction networks, integrated over the tree of life. Nucleic Acids Res 43(D1):D447-D452. https://doi.org/10.1093/nar/gku1003

29. Laskowski RA, MacArthur MW, Moss DS, Thornton JM (1993) PROCHECK: a program to check the stereochemical quality of protein structures. J Appl Crystallogr 26(2):283-291. https://doi.org/10.1107/S0021889892009944

30. Shahsavani N, Sheikhha MH, Yousefi H, Sefid F (2018) In silico homology modeling and epitope prediction of NadA as a potential vaccine candidate in Neisseria meningitidis. Int J Mol Cell Med 7:53

31. Sefid F, Bahrami AA, Darvish M, Nazarpour R, Payandeh Z (2019) In silico analysis for determination and validation of iron-regulated protein from Escherichia coli. Int J Peptide Res Ther 25(4):1523-1537. https://doi.org/10.1 007/s10989-018-9797-3

32. Jayasekara S, Ratnayake R (2019) Microbial cellulases: an overview and applications. In: Rodríguez Pascual A, Eugenio Martín ME (eds). Cellulose. IntechOpen, London. https://doi.org/10.5772/intechopen.84531

33. Song Y-H, Lee K-T, Baek J-Y, Kim MJ, Kwon MR, Kim Y-J, Park M-R, Ko H, Lee J-S, Kim K-S (2017) Isolation and characterization of a novel glycosyl hydrolase family 74 (GH74) cellulase from the black goat rumen metagenomic library. Folia Microbiol 62(3):175-181. https://doi.org/10.1007/s12223-016-0486-3

34. Lee K-T, Toushik SH, Baek J-Y, Kim J-E, Lee J-S, Kim K-S (2018) Metagenomic mining and functional characterization of a novel KG51 bifunctional cellulase/hemicellulase from black goat rumen. J Agric Food Chem 66(34): 9034-9041. https://doi.org/10.1021/acs.jafc.8b01449

35. Monza E, Acebes S, Lucas MF, Guallar V (2017) Molecular modeling in enzyme design, toward in silico guided directed evolution. In: Alcalde M (ed) Directed enzyme evolution: advances and applications, Springer, 257284. https://doi.org/10.1007/978-3-319-50413-1_10

36. Verma A, Singh VK, Gaur S (2016) Computational based functional analysis of Bacillus phytases. Comput Biol Chem 60:53-58. https://doi.org/10.1016/j. compbiolchem.2015.11.001

37. Pramanik K, Ghosh PK, Ray S, Sarkar A, Mitra S, Maiti TK (2017) An in silico structural, functional and phylogenetic analysis with three dimensional protein modeling of alkaline phosphatase enzyme of Pseudomonas aeruginosa. J Genet Eng Biotechnol 15(2):527-537. https://doi.org/10.1016/j. jgeb.2017.05.003

38. Dutta B, Banerjee A, Chakraborty P, Bandopadhyay R (2018) In silico studies on bacterial xylanase enzyme: structural and functional insight. J Genet Eng Biotechnol 16(2):749-756. https://doi.org/10.1016/j.jgeb.2018.05.003

39. Hoda A, Hysi L, Bozgo V, Sena L, others (2020) Structural and functional analysis of interferon gamma from Bos taurus by bioinformatic tools. Zhivotnov'dni Nauki/Bulgarian J Anim Husbandry 57:25-37 
40. Mohanta TK, Khan A, Hashem A, Abd-Allah EF, Al-Harrasi A (2019) The molecular mass and isoelectric point of plant proteomes. BMC Genomics 20:1-14

41. Prabhu D, Rajamanikandan S, Anusha SB, Chowdary MS, Veerapandiyan M, Jeyakanthan J (2020) In silico functional annotation and characterization of hypothetical proteins from Serratia marcescens FGl94. Biol Bull 47(4):319331. https://doi.org/10.1134/S1062359020300019

42. Guruprasad K, Reddy BB, Pandit MW (1990) Correlation between stability of a protein and its dipeptide composition: a novel approach for predicting in vivo stability of a protein from its primary sequence. Protein Eng, Design Sel 4(2):155-161. https://doi.org/10.1093/protein/4.2.155

43. Ikai A (1980) Thermostability and aliphatic index of globular proteins. J Biochem 88(6):1895-1898

44. Christopherson MR, Dawson JA, Stevenson DM, Cunningham AC, Bramhacharya S, Weimer PJ, Kendziorski C, Suen G (2014) Unique aspects of fiber degradation by the ruminal ethanologen Ruminococcus albus 7 revealed by physiological and transcriptomic analysis. BMC Genomics 15:113

45. Zhang B, Li J, Lu Q (2018) Prediction of 8-state protein secondary structures by a novel deep learning architecture. BMC Bioinformatics 19:1-13

46. Yadav PK, Singh G, Gautam B, Singh S, Yadav M, Srivastav U, Singh B (2013) Molecular modeling, dynamics studies and virtual screening of Fructose 1, 6 biphosphate aldolase-II in community acquired-methicillin resistant Staphylococcus aureus (CA-MRSA). Bioinformation 9(3):158-164. https://doi. org/10.6026/97320630009158

\section{Publisher's Note}

Springer Nature remains neutral with regard to jurisdictional claims in published maps and institutional affiliations.

\section{Submit your manuscript to a SpringerOpen ${ }^{\circ}$ journal and benefit from:}

- Convenient online submission

- Rigorous peer review

- Open access: articles freely available online

High visibility within the field

- Retaining the copyright to your article

Submit your next manuscript at $\boldsymbol{\nabla}$ springeropen.com 